\title{
Efficacy of Trunk Trap Nets and Insecticides Applied Alone and in Combination for Control of Tree-of-heaven Root Weevil Eucryptorrhynchus scrobiculatus in Ailanthus altissima Plantations
}

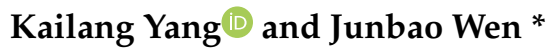 \\ Beijing Key Laboratory of Forest Pest Control, Beijing Forestry University, No. 35, Tsinghua East Rd., \\ Haidian District, 100083 Beijing, China; Yangk10423@163.com \\ * Correspondence: wenjb@bjfu.edu.cn; Tel.: +86-136-4129-8765
}

Received: 5 September 2019; Accepted: 16 October 2019; Published: 4 November 2019

\begin{abstract}
In Northern China, the tree-of-heaven root weevil (TRW), Eucryptorrhynchus scrobiculatus (Motschulsky) (Coleoptera: Curculionidae), is a serious borer pest of Ailanthus altissima (Mill.) Swingle (Sapindales: Simaroubaceae) (tree-of-heaven) is an important tree species for landscapes and afforestation. This study evaluates the efficacy of trunk trap nets (TTN), thiacloprid spray (TS), and cypermethrin spray (CS) alone, and in combination with TTN and thiacloprid or cypermethrin spray (TTNTS or TTNCS) for controlling TRW in A. altissima plantations in 2016-2018 in three sites (Haojiaqiao, Wutongshu, and Taojiajuan), which are located near Lingwu city in Ningxia, China. TTN, TTNTS, and TTNCS treatments significantly reduce marked TRW captures (more than 93\% with respect to the untreated trees) and wild TRW captures in population monitoring trunk trap nets (MTTN) deployed in stands (more than 55\% with respect to the untreated trees). Further field trials demonstrate that these TTN, TTNTS, and TTNCS treatments significantly reduce damage to A. altissima in stands; there are no significant differences between TTN and combination treatments. In addition, significantly more TRW are captured in MTTN within Taojiajuan than within Haojiaqiao or Wutongshu in field trials 2018. There were no significant differences between sites in 2016 and 2017. This study indicates that the TS and CS treatments used had very little to no impact on TRW populations and tree health in the timeframe examined. TTN alone are clearly effective for suppressing populations of TRW and stabilizing A. altissima tree health. This physical control technique, using TTN, could be sufficient to manage TRW on tree-of-heaven with no insecticide.
\end{abstract}

Keywords: Eucryptorrhynchus scrobiculatus; Ailanthus altissima trees; integrated pest management; physical control; trunk trap nets; insecticide sprays

\section{Introduction}

The tree-of-heaven, Ailanthus altissima (Mill.) Swingle (Sapindales: Simaroubaceae), is an excellent greening, ornamental, medicinal, oil, and afforestation tree species in China [1]. Due to its high tolerance for poor air quality and soils, tree-of-heaven grows well in less hilly areas and limestone areas $[1,2]$. The native tree species is the main afforestation species in North and Northwest China $[1,2]$. Tree-of-heaven is an important part of the landscape and the shelter-belts that have been widely planted in the Ningxia Hui Autonomous Region since 1980. At present, more than 27,333 ha of A. altissima trees have been planted in Ningxia. Bark, root bark, and the fruit of tree-of-heaven can also be used as medicine and have anti-malaria, anti-cancer, and anti-viral effects [3,4]. He et al. [5] provided evidence 
that ailanthone, extracted from A. altissima, is a promising compound against castration-resistant prostate cancer. However, the tree-of-heaven root weevil (TRW), Eucryptorrhynchus scrobiculatus (Motschulsky 1854) (Coleoptera: Curculionidae), has severe root-boring pests that poses a significant threat to tree-of-heaven and causes substantial damage in plantations [2,6].

The geographical distribution of TRW was restricted to the provinces of Beijing, Tianjin, Shandong, Shanxi, Shaanxi, Shanghai, Hubei, and Sichuan in China in 1980 [6], but has expanded rapidly thereafter due to frequent seedling transport under no strict quarantine. TRW was introduced in Yinchuan city, in the Ningxia Hui Autonomous Region, with seedling transport in 1999 [7]. Due to non-strict quarantine procedures and the lack of effective measures against TRW, this insect pest spread to all 23 cities and counties in Yinchuan, Shizuishan, Wuzhong, Zhongwei, and Guyuan cities in Ningxia in 2008. A total of 4180 ha of $A$. altissima trees were damaged and 1913 ha of A. altissima trees were killed in Ningxia in 2008 [7]. In 2015, more than 5333 ha of $A$. altissima trees were damaged. TRW has been defined as the provincial supplementary quarantine pest in Ningxia Hui Autonomous Region. Currently, TRW has spread throughout Northwestern, Northern, and a part of central, Northeastern, and Southwestern China [2,8-10].

TRW is reported to be univoltine in China and overwinters as adults and larvae in the soil at a depth of 20-30 cm near the base of A. altissima trees [2]. Females oviposit on the soil surface near tree trunks and lay as many as 156 eggs in a lifetime [10]. Eggs hatch in 7-10 days, and larvae develop under the root cortex, feeding on and destroying phloem and xylem, thereby weakening and sometimes killing the trees. Larvae progress through six instars in 60-75 days [2]. Individuals cease feeding before pupation, which occurs in long elliptic soil chambers. Pupation lasts 10-14 days, which produces teneral adults [2]. TRW emerge from the soil and begin to ascend trees until they reach the branches in order to satisfy the nutritional requirements for reproduction in April. Adults frequently walk on the tree trunk and feed on buds, shoots, and leaves, causing buds to wilt and compound leaves to fall off $[2,9,10]$. Adults can live for more than 200 days after emergence [2].

Management tactics for TRW include a variety of chemical, physical, and biological methods [8,11-17]. Different insecticides (e.g., cypermethrin, thiacloprid, fenoxycarb, acridine, carbosulfan, and imidacloprid) and application methods (e.g., sprays, soil drenches, and stem and soil injections) have been used against this pest $[11,13,14]$. Cypermethrin and thiacloprid sprays are more effective against TRW adults than other chemical methods [11]. Beauveria bassiana in aqueous suspension (Jiangxi Tianren Ecology Co., Ltd., Ji'an, China) has a high infection efficacy for TRW adults and larvae in the laboratory $[12,14]$. However, Beauveria bassiana in aqueous suspension, used by spraying and soil injection, had little impact on TRW populations in field trials [14]. Advances in the understanding of TRW biology led to the development of modified square trap nets (MSTN), trunk trap nets (TTN), and trunk barriers for controlling TRW [15-17]. TTN are more effective against adult TRW than trunk barriers and MSTN. In addition, the installation of MSTN requires at least $2 \times 2 \mathrm{~m}$ of flat land around the base of each tree in forest environments. TTN are more easily operated and are not limited by forest environments for the management of E. scrobiculatus, compared to MSTN.

The goal of this three-year (2016-2018) study is to assess the effects of TTN and insecticides applied alone and in combination for controlling TRW as they emerge from the soil. We performed field experiments designed to (1) test TTN, cypermethrin spray, and thiacloprid spray alone and the combinations of TTN and cypermethrin or thiacloprid spray against released and wild TRW, and (2) to evaluate the efficiency of these treatments in reducing tree damage (dieback and mortality).

\section{Materials and Methods}

\subsection{Study Sites}

Trials were conducted over a three-year period (2016-2018) on the following three sites: (1) Haojiaqiao (HJQ) (38 00' 25.92" N, 106¹7'36.57” E) near Southwestern Lingwu city; (2) Wutongshu (WTS) $\left(38^{\circ} 09^{\prime} 57.57^{\prime \prime} \mathrm{N}, 106^{\circ} 17^{\prime} 18.58^{\prime \prime} \mathrm{E}\right)$ near Northwestern Lingwu city and (3) Taojiajuan (TJJ) 
$\left(38^{\circ} 10^{\prime} 40.4^{\prime \prime} \mathrm{N}, 106^{\circ} 15^{\prime} 49.2^{\prime \prime} \mathrm{E}\right)$ near Northwestern Lingwu city. All three sites were plantations of A. altissima and trees at each site grew naturally. More detailed information of these sites is given by Yang et al. [16].

\subsection{Weevils}

Adult TRW were obtained from tree-of-heaven at the aforementioned sites and weevils were fed with fresh branches of $A$. altissima and water inside $30 \times 20 \times 10 \mathrm{~cm}$ cages for three days at $20^{\circ} \mathrm{C}-22^{\circ} \mathrm{C}$ and $50 \%-70 \%$ relative humidity before release.

\subsection{Treatments}

The following treatments were evaluated: (1) TTN, 11 mesh in size (Figure 1), (2) thiacloprid (2\% AI) (Jiangxi Heaven and Man Ecological Co., Ltd., Ji'an, China) and water at a 1:1000 ratio (v:v), (3) cypermethrin (4.5\% AI) (Shandong Zouping Pesticide Co., Ltd., Zouping, China) and water at a 1:1000 ratio (v:v), (4) the combination of TTN and thiacloprid, (5) the combination of TTN and cypermethrin, and (6) no pest management. TTN were affixed to every alternate tree at a height of $\sim 1 \mathrm{~m}$ above ground, as described by Yang et al. [16] (Figure 1). Each of the insecticides were sprayed with $0.25-0.3 \mathrm{~L}$ on every alternate tree with a new Xinyuan knapsack sprayer (Volume, $20 \mathrm{~L}$ ) (Zhejiang Taizhou Kaifeng Sprayer Factory, Taizhou, China).
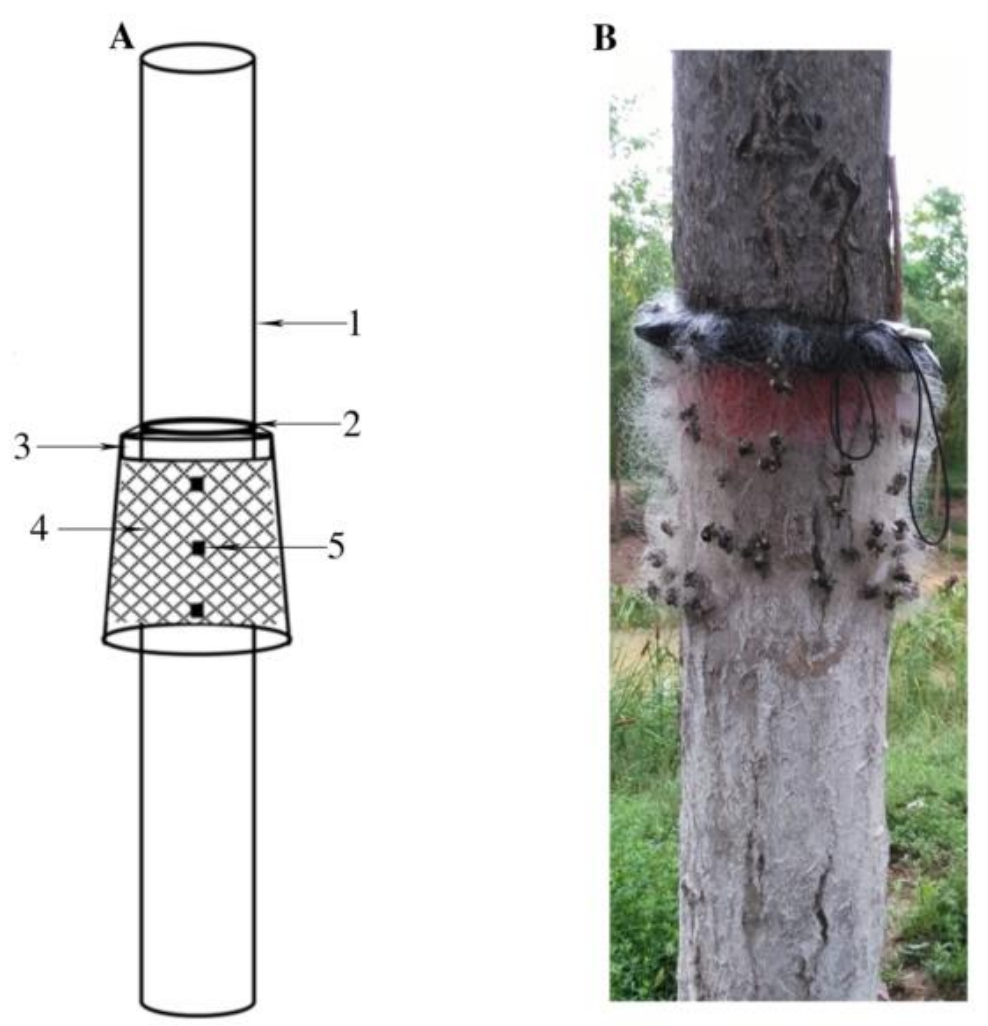

Figure 1. Trunk trap nets (TTN). (A) Diagram of the TTN. (B) TTN used in a field trial. (1) Tree trunk; (2) elastic; (3) spongy cushion; (4) netting; and (5) adhesive Velcro.

\subsection{Effects of TTN and Insecticides Applied Alone and in Combination on Released TRW}

In 2016, mark-release-recapture tests were performed at HJQ, WTS, and TJJ to compare the efficiency of the TTN, insecticide spray alone, and their combination in reducing released TRW density. The potential of the treatments to reduce released TRW was evaluated by monitoring TTN (MTTN) to assess the relative numbers of adult beetles within stands (Figure 2). The six treatments, i.e., TTN, thiacloprid spray (TS), cypermethrin spray (CS), TTN + thiacloprid spray (TTNTS), TTN + 
cypermethrin spray (TTNCS), and no pest management activities, were applied, as described above. At each of the three aforementioned sites, there were ten replicate blocks of each treatment in a randomized complete block design. The distance between neighboring treatment within block and neighboring blocks was $20 \mathrm{~m}$ and at least $50 \mathrm{~m}$, respectively. Jing Dian ${ }^{\circledR}$ blue oil paint was used to mark TRW adults prior to their release. Mark TRW were delivered to these sites from the lab. Starting at 8:00 am, 30 mixed-gender weevils were released around the base of each tested tree trunk. Approximately 1800 weevils were released at each site. The MTTN were tied to every tested tree trunk at a height of $\sim 1.5 \mathrm{~m}$ above the ground about two-weeks after the application of all treatments (Figure 2). MTTN were inspected once every two-weeks and marked TRW catches were recorded. MTTN and TTN were replaced at one-month intervals and the insecticide applications were applied monthly. Experiments were conducted from May to July.

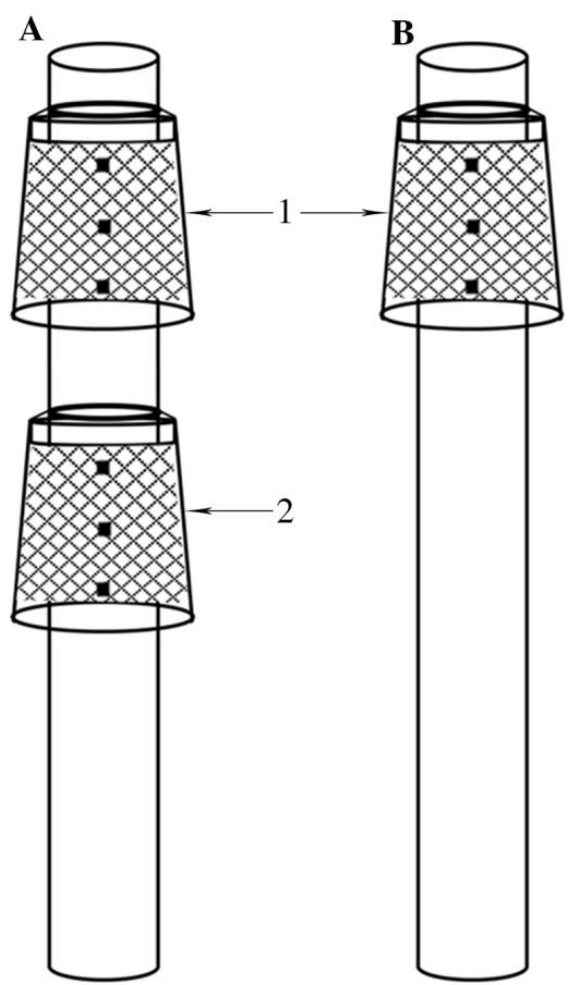

Figure 2. Diagram of the monitoring trunk trap net (MTTN). (1) MTTN. (2) TTN. (A) MTTN tied to tree trunks treated by TTN or combinations of TTN and thiacloprid or cypermethrin. (B) MTTN tied to tree trunks treated by thiacloprid, cypermethrin, or untreated tree trunks. The top of the MTTN was $\sim 1.5 \mathrm{~m}$ above the ground. The top of the TTN was $\sim 1 \mathrm{~m}$ above the ground.

\subsection{Effects of TTN and Insecticides Alone and in Combination on Wild TRW}

From 2017 to 2018, trials were performed at HJQ, WTS, and TJJ to compare the effectiveness of the TTN, insecticide spray alone, and their combination in reducing natural TRW populations. The six treatments were applied, as described above. There were ten replicate blocks of each treatment in a randomized complete block design. Each treatment within each block was randomly assigned to a group of six adjacent trees (60 trees per location). The distance between neighboring blocks was at least $50 \mathrm{~m}$. The MTTN were tied to every tested tree trunk at a height of $\sim 1.5 \mathrm{~m}$ above the ground about two-weeks after the application of all treatments (Figure 2). Experiments were conducted from May 6 to October 10, and MTTN were inspected once every two-weeks. MTTN and TTN were replaced at one-month intervals and the insecticide applications were applied monthly. 


\subsection{Evaluation of Damage to A. altissima Trees}

From 2016 to 2018, trials were performed at TJJ to assess whether TTN, insecticide spray alone, and their combination, could be used to reduce TRW damage to A. altissima trees. There were three blocks at the location and each block consisted of six plots of 1 ha, each in a randomized complete block design. The distance between neighboring plots and blocks was $50 \mathrm{~m}$ and $100 \mathrm{~m}$, respectively. In each plot, one of the treatments was applied, as described above. All treatments were applied on April 23-26 of every year. We selected 90 A. altissima trees in every plot to assess canopy dieback twice (June and August) every year, based on visual assessments using the following scale: $0 \%$ (healthy) to $100 \%$ (dead). All treatments were replaced at one-month intervals and were deployed until October 7 each year.

\subsection{Data Analysis}

Shapiro-Wilk and Levene tests were used to determine whether all dependent variables met normality and homoscedasticity. The number of TRWs captured was transformed to $\log (x+1)$ to achieve normality and homogeneity [18]. For capture data, we used a mixed-model ANOVA with the control method (TTN, thiacloprid spray, and cypermethrin spray alone, and the combinations of TTN and thiacloprid or cypermethrin spray), site and the interaction between the control method and the site, as fixed factors, and block as a random factor. When the results were significant, we performed one-way ANOVA with Tukey's test to determine the differences in the number of TRWs captured in MTTN among TTN-treated, TS-treated, CS-treated, TTNTS-treated, TTNCS-treated, and untreated control trees within the sites. In addition, we performed one-way ANOVA with Tukey's test to determine the differences in the number of TRWs captured between the sites. Mortality and canopy dieback data could not be transformed to meet the assumptions of parametric tests; therefore, Kruskal-Wallis tests were used to determine the differences among TTN-treated, TS-treated, CS-treated, TTNTS-treated, TTNCS-treated, and untreated control trees [19]. All analyses were conducted at the $\alpha=0.05$ level of significance using SPSS 23.0 [20].

\section{Results}

\subsection{Effects of TTN and Insecticides Applied Alone and in Combination on Released TRW}

In 2016, the treatment had significant effects on the number of marked TRWs captured in MTTN, whereas site and interaction between treatments and site was not significant (Tables 1 and 2). At HJQ, WTS, and TJJ locations, significantly fewer marked TRW were caught in MTTN on TTN-treated, TTNTS-treated, or TTNCS-treated trees than on TS-treated, CS-treated, or untreated trees (HJQ: $F_{5,59}=80.83, p<0.001$; WTS: $F_{5,59}=36.31, p<0.001 ;$ TJJ: $F_{5,59}=37.36$, and $p<0.001$; Figure 3A). Relative to the control, the number of marked TRW were reduced by $93.3 \%, 94.9 \%$, and $93.4 \%$ for TTN, TTNTS, and TTNCS, respectively. The number of marked TRW in MTTN did not differ among TTN-treated, TTNTS-treated, or TTNCS-treated trees (Figure 3A). Additionally, the number of marked TRW in MTTN on TS-treated, CS-treated, or control trees did not have statistical differences (Figure 3A).

Table 1. Effect of treatment [control methods: Trunk trap nets and insecticides applied alone (thiacloprid or cypermethrin spray) and in combination] and site on the number of captured tree-of-heaven root weevils (TRW) in monitoring trunk trap nets (MTTN).

\begin{tabular}{cccccccccc}
\hline \multirow{2}{*}{ Source } & \multicolumn{3}{c}{ Number of marked TRW in 2016 } & \multicolumn{3}{c}{ Number of wild TRW in 2017 } & \multicolumn{4}{c}{ Number of wild TRW in 2018 } \\
\cline { 2 - 10 } & $\mathbf{d f}$ & $\boldsymbol{F}$ & $\boldsymbol{p}$ & $\mathbf{d f}$ & $\boldsymbol{F}$ & $\boldsymbol{p}$ & $\mathbf{d f}$ & $\boldsymbol{F}$ & $\boldsymbol{p}$ \\
\hline Site & 2 & 1.41 & 0.25 & 2 & 2.25 & 0.11 & 2 & 22.88 & $<0.001$ \\
Treatment & 5 & 76.78 & $<0.001$ & 5 & 32.35 & $<0.001$ & 5 & 46.26 & $<0.001$ \\
Treatment $\times$ Site & 10 & 0.76 & 0.67 & 10 & 0.34 & 0.97 & 10 & 1.84 & 0.58 \\
Total & 153 & & & 153 & & & 153 & & \\
\hline
\end{tabular}



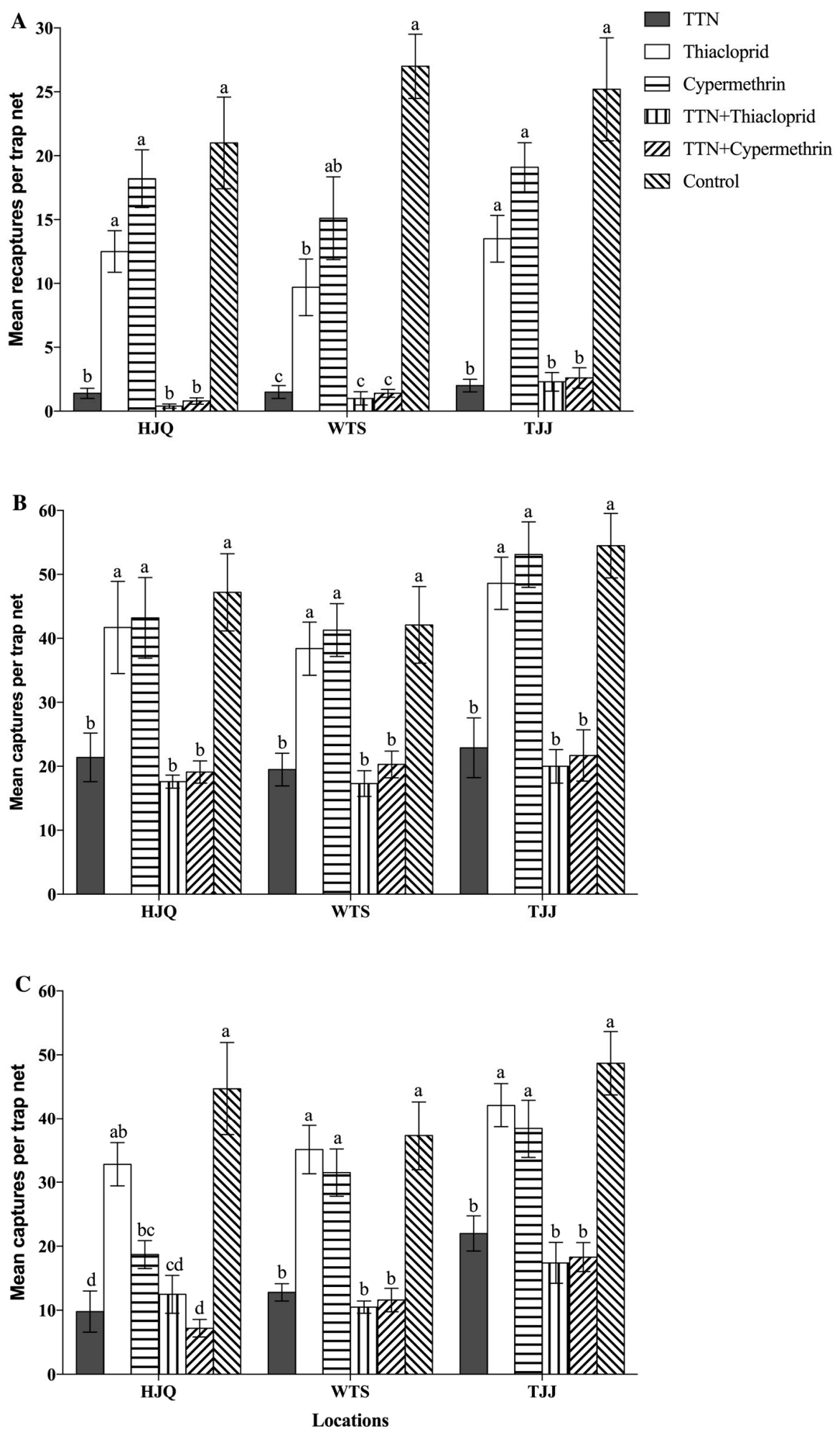

Figure 3. The number (means \pm SE) of tree-of-heaven root weevils (TRW), Eucryptorrhynchus scrobiculatus, caught per monitoring trunk trap net (MTTN) on trees that were either untreated or treated with the trunk trap net (TTN), insecticide (thiacloprid or cypermethrin) sprays, or their combination at Haojiaqiao (HJQ), Wutongshu (WTS), and Taojiajuan (TJJ). (A) The number of captured and marked TRWs in 2016. (B) The number of captured wild TRWs in 2017. (C) The number of captured wild weevils in 2018. Columns with the same letter were not significantly different (Tukey's HSD, $\alpha=0.05$ ). 
Table 2. The number (means \pm SE) of tree-of-heaven root weevils (TRW), Eucryptorrhynchus scrobiculatus, caught per monitoring trunk trap net (MTTN) on trees at Haojiaqiao (HJQ), Wutongshu (WTS), and Taojiajuan (TJJ). Means followed by different letters within the same column are significantly different (Tukey's HSD, $\alpha=0.05$ ).

\begin{tabular}{cccc}
\hline Site & $\begin{array}{c}\text { Number of marked } \\
\text { TRW in 2016 }\end{array}$ & $\begin{array}{c}\text { Number of wild TRW } \\
\text { in 2017 }\end{array}$ & $\begin{array}{c}\text { Number of wild TRW } \\
\text { in 2018 }\end{array}$ \\
\hline HJQ & $9.05 \pm 1.33$ & $31.7 \pm 2.52$ & $20.95 \pm 2.32 \mathrm{~b}$ \\
WTS & $9.28 \pm 1.45$ & $29.82 \pm 2.04$ & $23.13 \pm 1.97 \mathrm{~b}$ \\
TJJ & $10.78 \pm 1.43$ & $36.8 \pm 2.63$ & $31.15 \pm 2.15 \mathrm{a}$ \\
\hline
\end{tabular}

\subsection{Effects of TTN and Insecticides Applied Alone and in Combination on Wild TRW}

In 2017, there was a significant effect of the treatment on the number of wild TRW captured in MTTN, but site and interaction of control methods and sites did not have a significant influence on wild TRW numbers in MTTN (Tables 1 and 2). At all three locations, significantly fewer wild TRW were caught in MTTN on TTN-treated, TTNTS-treated, or TTNCS-treated trees than on TS-treated, CS-treated, or untreated trees (HJQ: $F_{5,59}=9.48, p<0.001$; WTS: $F_{5,59}=9.51, p<0.001$; TJJ: $F_{5,59}=12.93$, and $p<0.001$; Figure 3B). Relative to the control, wild TRW numbers were reduced by $55.6 \%, 61.8 \%$, and $57.5 \%$ for TTN, TTNTS, and TTNCS, respectively. The number of marked TRWs in MTTN did not differ within TTN-treated, TTNTS-treated, or TTNCS-treated trees (Figure 3B). Additionally, the number of wild TRWs in MTTN on TS-treated, CS-treated, or control trees also did not have statistical differences (Figure 3B).

In 2018, there was a significant effect of the treatment and site on the number of wild TRWs captured in MTTN (Table 1). However, the interaction of control methods and sites did not significantly influence wild TRW numbers in MTTN (Tables 1 and 2). Significantly more wild TRWs were captured in MTTN within the TJJ location than within the HJQ or WTS locations (Table 2). There were no significant differences between the HJQ and WTS locations (Table 2). At all three locations, significantly fewer wild TRWs were caught in MTTN on TTN-treated, TTNTS-treated, or TTNCS-treated trees than on TS-treated, CS-treated, or untreated trees (HJQ: $F_{5,59}=15.71, p<0.001$; WTS: $F_{5,59}=21.03$, $p<0.001$; TJJ: $F_{5,59}=14.25$, and $p<0.001$; Figure 3C). Relative to the control, wild TRW numbers were reduced by $65.9 \%, 69.1 \%$, and $71.6 \%$ for TTN, TTNTS, and TTNCS, respectively. The number of marked TRWs in MTTN did not differ within TTN-treated, TTNTS-treated, or TTNCS-treated trees (Figure 3C). Additionally, the number of wild TRWs in MTTN also did not have statistical differences within TS-treated, CS-treated, or control trees (Figure 3C).

\subsection{Evaluation of Damage to Tree-of-heaven}

We did not find that the canopy dieback of A. altissima trees significantly differed among TTN-treated, TS-treated, CS-treated, TTNTS-treated, TTNCS-treated, and untreated plots in 2016 $\left(\chi^{2}=1.489 ; \mathrm{df}=5 ; p=0.914\right)$ (Table 3). In 2017 and 2018, significantly higher canopy dieback was found in TS-treated, CS-treated, and control plots than in TTN-treated, TTNTS-treated, and TTNCS-treated ones (2017: $\chi^{2}=13.195 ; \mathrm{df}=5 ; p=0.022 ; 2018: \chi^{2}=13.464 ; \mathrm{df}=5$; and $p=0.019$ ) (Table 3). In 2016, we did not detect that any A. altissima trees were killed within the experimental plot (Table 3). While we found dead A. altissima trees within TS-treated and untreated plots in 2017, there were no significant differences in A. altissima mortality among TTN-treated, TS-treated, CS-treated, TTNTS-treated, TTNCS-treated, and untreated plots $\left(\chi^{2}=9.644 ; \mathrm{df}=5 ; p=0.086\right)$ (Table 3). In 2018, tree mortality significantly differed among TTN-treated, TS-treated, CS-treated, TTNTS-treated, TTNCS-treated, and untreated plots $\left(\chi^{2}=12.965 ; \mathrm{df}=5\right.$; and $\left.p=0.024\right)$ (Table 3). Significantly higher tree mortality was found in TS-treated, CS-treated, or untreated plots than in TTN-treated, TTNTS-treated, or TTNCS-treated plots (Table 3). 
Table 3. The tree-of-heaven weevil (TRW), Eucryptorrhynchus scrobiculatus, damage (means $\pm \mathrm{SE}$, expressed as a percentage) to tree-of-heaven Ailanthus altissima at Haojiaqiao, Lingwu city of Ningxia, China (2016-2018). Means followed by different letters within the same column are significantly different (Kruskal-Wallis test, $\alpha=0.05)$.

\begin{tabular}{ccccccc}
\hline \multirow{2}{*}{ Treatments } & \multicolumn{2}{c}{2016} & \multicolumn{2}{c}{$\mathbf{2 0 1 7}$} & \multicolumn{2}{c}{2018} \\
\cline { 2 - 6 } & $\begin{array}{c}\text { Mortality } \\
(\mathbf{\% )}\end{array}$ & $\begin{array}{c}\text { Canopy } \\
\text { Dieback (\%) }\end{array}$ & $\begin{array}{c}\text { Mortality } \\
\mathbf{( \% )}\end{array}$ & $\begin{array}{c}\text { Canopy } \\
\text { Dieback (\%) }\end{array}$ & $\begin{array}{c}\text { Mortality } \\
\mathbf{( \% )}\end{array}$ & $\begin{array}{c}\text { Canopy } \\
\text { Dieback (\%) }\end{array}$ \\
\hline TTN $^{1}$ & $0 \pm 0$ & $6.4 \pm 1.9$ & $0 \pm 0$ & $7.0 \pm 1.8 \mathrm{~b}$ & $0 \pm 0 \mathrm{~b}$ & $8.7 \pm 1.2 \mathrm{~b}$ \\
TS $^{1}$ & $0 \pm 0$ & $4.1 \pm 1.3$ & $0.7 \pm 0.4$ & $13.2 \pm 1.2 \mathrm{a}$ & $2.9 \pm 1.0 \mathrm{a}$ & $29.0 \pm 4.4 \mathrm{a}$ \\
CS $^{1}$ & $0 \pm 0$ & $5.2 \pm 1.3$ & $0 \pm 0$ & $14.4 \pm 1.8 \mathrm{a}$ & $2.6 \pm 1.6 \mathrm{a}$ & $27.2 \pm 6.8 \mathrm{a}$ \\
TTNTS $^{1}$ & $0 \pm 0$ & $4.4 \pm 0.6$ & $0 \pm 0$ & $4.8 \pm 0.7 \mathrm{~b}$ & $0 \pm 0 \mathrm{~b}$ & $6.6 \pm 0.9 \mathrm{~b}$ \\
TTNCS $^{1}$ & $0 \pm 0$ & $4.7 \pm 0.4$ & $0 \pm 0$ & $5.7 \pm 0.8 \mathrm{~b}$ & $0 \pm 0 \mathrm{~b}$ & $7.5 \pm 0.9 \mathrm{~b}$ \\
Control & $0 \pm 0$ & $4.7 \pm 0.8$ & $1.1 \pm 0.6$ & $15.5 \pm 2.5 \mathrm{a}$ & $4.1 \pm 1.5 \mathrm{a}$ & $31.0 \pm 6.7 \mathrm{a}$ \\
\hline
\end{tabular}

${ }^{1}$ TTN: Trunk trap nets; TS: Thiacloprid spray; and CS: Cypermethrin spray; TTNTS: the combinations of TTN and thiacloprid spray; TTNCS: the combinations of TTN and cypermethrin spray.

\section{Discussion}

In this study, we evaluated the efficacy of novel trunk trap nets (TTN) and insecticides applied alone (thiacloprid or cypermethrin spray) and in combination on released and wild tree-of-heaven root weevil (TRW) populations in plantations of A. altissima. Our experiments showed that novel TTN and combinations of the TTN and cypermethrin or thiacloprid sprays were clearly more effective in reducing TRW adults than the cypermethrin or thiacloprid spray alone. The application of TTN and their combination with cypermethrin or thiacloprid spray can reduce damage to trees.

Based on the specific routes of some insect pests walking on tree trunks, some trunk trap devices have been developed and showed great potential for managing these pests. The efficacy of trunk barrier trap devices was up to $99.8 \%$ and $99.6 \%$ in capturing Thaumetopoea pityocampa (Lepidoptera: Thaumetopoeidae) wintering larvae, owing to the fact that they leave the tree in a litany procession during the daytime during late winter and early spring [21]. The performance of TTN was efficient in capturing TRW adults walking on the tree trunks. Our study demonstrated that marked TRW numbers decreased by more than $93 \%$ after TTN application relative to the control. These results are similar to those of a previous study in which $84.8 \%$ of marked TRWs were captured by the TTN [16].

The management of TRW relies exclusively on frequent applications of many synthetic insecticides, owing to the lack of effective non-chemical control methods over the past 10 years or longer in the Ningxia Hui Autonomous Region. The unreasonable use of pesticides can cause several environmental problems, such as soil and ground water contamination, and have effects on wildlife and human health, selection of resistant populations of target organisms, resurgence of secondary pests, and negative effects on beneficial arthropods [22-24]. As plantations of A. altissima are close to farmlands and irrigation canals in Ningxia, frequent use of pesticides in A. altissima plantations may also have negative impacts on farmlands, as described above. The efficacy of chemical treatments (i.e., cypermethrin and thiacloprid sprays) is well known $[11,13,14]$. However, chemical treatments did not effectively reduce weevil populations and chemically treated plots showed declining health in this study. This demonstrates that chemical treatments alone cannot suppress populations of TRW and stabilize A. altissima tree health. TRW may have evolved insecticide resistance, making insecticides completely ineffective for TRW in this study. The issue of insecticide resistance will be a focus of our future work.

Combinations of different control methods are useful for the development of effective pest management strategies. The application of chemical insecticide sprays could rapidly suppress insect pest population density. Chemical insecticides and other methods (e.g., microbial control agents, attractants, and classical biological control agents) have additive or synergistic effects on insect pests [24-31] and can be conducive to reducing insecticide use and costs [32,33]. However, no 
additive or synergistic effects on TRW populations and tree health, and the survival between TTN and insecticides, were found in this study.

Mark-release-recapture techniques are effective for assessing the efficacy of traps, exploring the dispersal behavior of insects, and interpreting evidence for changes in the population structure. The paint marking technique is durable, nontoxic, fast-drying, and easy to apply. It has been successfully applied to several forest pests, such as Phoracantha semipunctata (Fabricius) [34], Anoplophora glabripennis Motschulsky [35], Cerambyx welensii Küster (Coleoptera: Cerambycidae) [36], Hylobius pales (Herbst) [37], Pachylobius picivorus (Germar) [37], E. scrobiculatus (Motschulsky) [16], and E. brandti (Harold) (Coleoptera: Curculionidae [38]. By marking the beetles, it was possible to evaluate similar beetle densities at all experimental sites and to estimate the capture efficiency of different control methods. Therefore, there were no significant effects of site on the number of marked TRW captured in MTTN in mark-release-recapture field trials in 2016, which is consistent with the results of previous studies $[15,16]$. In addition, there were also no significant effects of site in field trials in 2017, whereas significant site effects were found in field trials in 2018. This may be because the wild TRW population density has changed in different sites in 2017 and 2018. In future work, we will use TTN to explore the dispersal behavior of E. scrobiculatus and evaluate changes in the TRW population density by mark-release-recapture tests. Factors potentially affecting TRW population density will also be studied, including tree age, soil types, temperature, humidity, and other meteorological factors.

The total cost of the TTN was estimated to be US $\$ 345.84$ per hectare per season in plantations of A. altissima, compared with $\$ 49.03$ and $\$ 45.07$ US per hectare per season for TS and CS, respectively (including labor costs) (Table 4). While the process of hand-making TTN is simple, purely hand-made nets show low production efficiency and high production costs compared with the industrial mass production of chemical insecticides. The efficiency and costs will vary depending on the productivity of workers, but about 30 TTN can be made every hour, which explains the higher cost of TTN for controlling weevils than chemical insecticides. Thus, the industrial mass production of TTN should be promoted to reduce weevil control costs. In addition, the optimum time for the replacement of TTN should also be studied to improve capture efficiency and reduce costs. TTN can use helpful and eco-friendly measures for suppressing the TRW population and stabilizing A. altissima tree health. The number of infested tree-of-heavens is continuing to increase in Ningxia, and therefore, an area-wide and long-term control program using TTN for the management of TRW should be implemented. Consistent with previous results [16], we found that an amount of fourth instar nymph and adult Lycorma delicatula white (Hemiptera: Fulgoridae) were captured by TTN (Figures S1 and S2), suggesting that the method may be used to manage spotted lanternfly. We did not find that the first instars were captured by the TTN. This may be because the TTN, $11 \mathrm{~mm}$ mesh size, were too large to capture the first instars or there were behavioral differences between the first instars and late instar on A. altissima tree trunks. Future studies will evaluate the efficiency of the different TTN in capturing spotted lanternfly.

Table 4. Cost of control methods (TTN, TS, CS, TTNTS, and TTNCS) per hectare per season.

\begin{tabular}{cccc}
\hline \multirow{2}{*}{ Treatments } & \multicolumn{3}{c}{ Cost $\mathbf{( \$ )}$} \\
\cline { 2 - 4 } & Product & Labor & Total Cost \\
\hline TTN $^{1}$ & 255 & 90.84 & 345.84 \\
TS $^{1}$ & 9.89 & 39.14 & 49.03 \\
CS $^{1}$ & 5.93 & 39.14 & 45.07 \\
TTNTS $^{1}$ & 264.89 & 129.98 & 394.87 \\
TTNCS $^{1}$ & 260.93 & 129.98 & 390.91 \\
\hline
\end{tabular}

${ }^{1}$ TTN: Trunk trap nets; TS: Thiacloprid spray; CS: Cypermethrin spray; TTNTS: Combination of TTN and thiacloprid spray; TTNCS: Combination of TTN and cypermethrin spray. 


\section{Conclusions}

In summary, our data showed that TTN treatments were clearly effective for suppressing populations of TRW and stabilizing A. altissima tree health. Chemical treatments (thiacloprid spray or cypermethrin spray) alone did not effectively reduce weevil populations and chemically treated plots showed declining tree health. We also did not find additive or synergistic effects on TRW populations and tree health and survival using combinations of insecticides and TTN in this study. TRW usually began to emerge at the end of April; hence, to maximize the benefits of TTNs, they should be deployed before this time.

Supplementary Materials: The following are available online at http:/www.mdpi.com/1999-4907/10/11/972/s1, Figure S1: Fourth instar nymph Lycorma delicatula captured in a TTN, Figure S2: Adult Lycorma delicatula captured in a TTN.

Author Contributions: K.Y. and J.W. conceived and designed research. K.Y. conducted experiments. K.Y. analyzed data and wrote the manuscript. All authors read and approved the manuscript.

Funding: This work was supported by the National Key R \& D Program of China (Grant number: 2018YFC1200400).

Acknowledgments: We thank Lingwu Forestry Bureau for providing us with insecticides. We would also like to thank all of the people that helped carry out fieldwork and data collection.

Conflicts of Interest: The authors report no conflicts of interest with this manuscript.

\section{References}

1. Shen, J.M.; Liu, Z.C.; Zhang, W.Q.; Fan, Z.W.; Liu, G.S. The review of Ailanthus altissima (Mill.) Swingle (Sapindales: Simaroubaceae). J. Henan For. Sci. Technol. 2008, 28, 27-28.

2. Yang, G.J.; Yong, H.L.; Wang, X.P. The biological characters and behavior of Eucryptorrhynchus chinensis. Chin. Bull. Entomol. 2008, 45, 65-69.

3. Guo, Z.; Vangapandu, S.; Sinderlar, R.W.; Walker, L.A.; Sindelar, R.D. Biologically active quassinoids and their chemistry: Potential leads for drug design. Curr. Med. Chem. 2005, 12, 173-190. [CrossRef] [PubMed]

4. Jin, M.; Yook, J.; Lee, E.; Lin, C.X.; Quan, Z.; Son, K.H.; Bae, K.H.; Kim, H.P.; Kang, S.S.; Chang, H.W. Anti-inflammatory activity of Ailanthus altissima in ovalbumin-induced lung inflammation. Biol. Pharm. Bull. 2006, 29, 884-888. [CrossRef]

5. He, Y.; Peng, S.; Wang, J.; Chen, H.; Cong, X.; Chen, A.; Hu, M.C.; Qin, M.; Wu, H.G.; Gao, S.M.; et al. Ailanthone targets $\mathrm{p} 23$ to overcome MDV3100 resistance in castration-resistant prostate cancer. Nat. Commun. 2016, 7, 13122. [CrossRef]

6. Zhao, Y.C.; Chen, Y.Q. Economic insect fauna of China (Fasc. 20) Coleoptera: Curculionidae (I); Science Press: Beijing, China, 1980; pp. 149-150.

7. PRC State Council Office. "Forestry Pest Warning Bulletin" regarding Eucryptorrhynchus scrobiculatus in the Ningxia Hui Autonomous Region. 2008. CN 200802. Available online: http://news.hexun.com/2008-10-09/ 109651295.html (accessed on 17 August 2019).

8. Tong, Z.L.; Gao, W.C.; Cao, Q.; Shan, J.G.; Qi, Q.S.; Wang, Y.X.; Lei, J.W.; Zheng, G.; Zhang, L.H. Studies on the infectivity of Steinernema feltiae to Eucryptorrhynchus chinensis and E. brandti. Chin. J. Biol. Control 1993, 9, 173-174.

9. Yu, Q.Q.; Chen, C.; Liu, Z.K.; Sun, Y.W.; Cao, C.J.; Bao, S.; Wen, J.B. Occurrence and life-history of Eucryptorrhynchus chinensis in Lingwu, Ningxia. Chin. J. Appl. Entomol. 2012, 49, 1005-1009.

10. Zhang, Y.; Wu, Z.M.; Yang, P.; Cao, C.J.; Sun, Y.W.; Wen, J.B. Effect of nutritional supplement on the fecundity of Eucryptorrhynchus chinensis (Olivier). J. Nanjing For. Univ. (Nat. Sci. Ed.) 2015, 35, 183-186.

11. Hou, J.; He, F.P. Analyzing damage and control measures of Eucryptorrhynchus chinensis and E. brandti. Chin. Agric. Technol. 2017, 37, 67+200.

12. Lei, L.; Wang, M.J.; Wang, J.H.; Qin, F.; Liu, C.; Ding, J.W.; Li, M.; Liu, Q. Pathogenicity of Beauveria bassiana to adults of two species of Eucryptorrhynchus under different temperatures and humidities. J. Tianjin Normal Univ. (Nat. Sci. Ed.) 2013, 33, 70-73. 
13. Wu, S.H.; Wang, J.G.; Lang, X.R.; Sun, P.; Xing, L.R.; He, Z.Y. Preliminary study on integrated prevention and control technology of Eucryptorrhynchus chinensis and E. brandti in Ningxia, China. Chin. Agric. Technol. 2012, 32, 50-51.

14. Yang, P. A Preliminary Study of the Artificial Raising and Control of Eucryptorrhynchus chinensis. Master's Thesis, Beijing Forestry University, Beijing, China, 2015.

15. Yang, K.L.; Wen, X.J.; Ren, Y.; Wen, J.B. Control of Eucryptorrhynchus scrobiculatus (Coleoptera: Cuculionidae), a major pest of Ailanthus altissima (Sapindales: Simaroubaceae), using a modified square trap net. J. Econ. Entomol. 2018, 111, 1760-1767. [CrossRef] [PubMed]

16. Yang, K.L.; Wen, X.J.; Ren, Y.; Wen, J.B. Novel trunk trap net designs for the control of Eucryptorrhynchus scrobiculatus (Coleoptera: Curculionidae). Pest. Manag. Sci. 2019, 75, 2618-2626. [CrossRef] [PubMed]

17. Li, F. A Kind of Barrier Devices for Preventing Eucryptorrhynchus brandti and E. scrobiculatus. C.N. Patent 2,009,201,442,297, 30 October 2019.

18. Zar, J.H. Biostatistical Analysis, 5th ed.; Pearson Prentice Hall: Bergen, NJ, USA, 2010.

19. Kruskal, W.H.; Wallis, W.A. Use of ranks in one-criterion variance analysis. J. Am. Stat. Assoc. 1952, 47, 583-621. [CrossRef]

20. IBM Corp. IBM SPSS Statistics for Windows; Version 23.0; IBM Corp: Armonk, NY, USA, 2015.

21. Colacci, M.; Kavallieratos, N.G.; Athanassiou, C.G.; Boukouvala, M.C.; Rumbos, C.I.; Kontodimas, D.C.; David, P.; Sancho, J.; Benavent-Fernández, E.; Gálvez-Settier, S.; et al. Management of the pine processionary moth, Thaumetopoea pityocampa (Lepidoptera: Thaumetopoeidae), in urban and suburban areas: Trials with trunk barrier and adhesive barrier trap devices. J. Econ. Entomol. 2018, 111, 227-238. [CrossRef] [PubMed]

22. Siqueira, H.Á.A.; Guedes, R.N.C.; Picanço, M.C. Insecticide resistance in populations of Tuta absoluta (Lepidoptera: Gelechiidae). Agric. For. Entomol. 2000, 2, 147-153. [CrossRef]

23. Desneux, N.; Decourtye, A.; Delpuech, J.M. The sublethal effects of pesticides on beneficial arthropods. Annu. Rev. Entomol. 2007, 52, 81-106. [CrossRef]

24. Soares, M.A.; Campos, M.R.; Passos, L.C.; Carvalho, G.A.; Haro, M.M.; Lavoir, A.V.; Biondi, A.; Zappalà, L.; Desneux, N. Botanical insecticide and natural enemies: A potential combination for pest management against Tuta absoluta. J. Pest. Sci. 2019, 92, 1433-1443. [CrossRef]

25. Bello, G.D.; Padin, S.; López Lastra, C.; Fabrizio, M. Laboratory evaluation of chemical-biological control of the rice weevil (Sitophilus oryzae L.) in stored grains. J. Stored. Prod. Res. 2000, 37, 77-84. [CrossRef]

26. Choe, D.H.; Tsai, K.; Lopez, C.M.; Campbell, K. Pheromone-assisted techniques to improve the efficacy of insecticide sprays against Linepithema humile (Hymenoptera: Formicidae). J. Econ. Entomol. 2014, 107, 319-325. [CrossRef]

27. Kungu, M.; Deletre, E.; Subramanian, S.; Fiaboe, K.K.; Gitonga, L.; Lagat, Z.O.; Martin, T. A new mite IPM strategy: Predator avoidance behaviour resulting from the synergetic effects of predator release and acaricide-treated nets. Pest. Manag. Sci. 2019, 75, 979-985. [CrossRef] [PubMed]

28. Greenberg, S.M.; Sappington, T.W.; Elzen, G.W.; Norman, J.W.; Sparks, A.N. Effects of insecticides and defoliants applied alone and in combination for control of overwintering boll weevil (Anthonomus grandis; Coleoptera: Curculionidae)—Laboratory and field studies. Pest. Manag. Sci. 2004, 60, 849-858. [CrossRef] [PubMed]

29. Mbata, G.N.; Shapiro-Ilan, D. The potential for controlling Pangaeus bilineatus (Heteroptera: Cydnidae) using a combination of entomopathogens and an insecticide. J. Econ. Entomol. 2013, 106, 2072-2076. [CrossRef] [PubMed]

30. Rahman, T.; Broughton, S. Suppressing Mediterranean fruit fly (Diptera: Tephritidae) with an attract-and-kill device in pome and stone fruit orchards in Western Australia. Crop. Prot. 2016, 80, 108-117. [CrossRef]

31. Shapiro-Ilan, D.I.; Cottrell, T.E.; Wood, B.W. Effects of combining microbial and chemical insecticides on mortality of the pecan weevil (Coleoptera: Curculionidae). J. Econ. Entomol. 2011, 104, 14-20. [CrossRef]

32. Chen, R.Z.; Klein, M.G.; Sheng, C.F.; Li, Y.; Shao, D.X.; Li, Q.Y. Use of pheromone timed insecticide applications integrated with mating disruption or mass trapping against Ostrinia furnacalis (Lepidoptera: Pyralidae) in sweet corn. Environ. Entomol. 2013, 42, 1390-1399. [CrossRef]

33. Davidson, W.; Rieske, L.K. Establishment of classical biological control targeting emerald ash borer is facilitated by use of insecticides, with little effect on native arthropod communities. Biol. Control 2016, 101, 78-86. [CrossRef] 
34. Hanks, L.M.; Millar, J.G.; Paine, T.D. Dispersal of the eucalyptus longhorned borer (Coleoptera: Cerambycidae) in urban landscapes. Environ. Entomol. 1998, 27, 1418-1424. [CrossRef]

35. Wen, J.B.; Li, Y.C.; Xia, N.B.; Luo, Y.Q. Study on dispersal pattern of Anoplophora glabripennis adults in poplars. Acta Ecol. Sin. 1998, 18, 269-277.

36. Torres-Vila, L.M.; Sanchez-González, Á.; Ponce-Escudero, F.; Martín-Vertedor, D.; Ferrero-García, J.J. Assessing mass trapping efficiency and population density of Cerambyx welensii Küster by mark-recapture in dehesa open woodlands. Eur. J. For. Res. 2012, 131, 1103-1116. [CrossRef]

37. Rieske, L.K.; Raffa, K.F. Dispersal patterns and mark-and-recapture estimates of two pine root weevil species, Hylobius pales and Pachylobius picivorus (Coleoptera: Curculionidae), in Christmas tree plantations. Environ. Entomol. 1990, 19, 1829-1836. [CrossRef]

38. Yang, K.L.; Wen, X.J.; Guo, W.J.; Wen, J.B. A novel adhesive trunk trap net for trapping Eucryptorrhynchus brandti (Coleoptera: Curculionidae). Pest. Manag. Sci. 2019. [CrossRef] [PubMed]

(C) 2019 by the authors. Licensee MDPI, Basel, Switzerland. This article is an open access article distributed under the terms and conditions of the Creative Commons Attribution (CC BY) license (http://creativecommons.org/licenses/by/4.0/). 